\title{
Aesthetics-What? Why? and Wherefore?
}

It is a very great honor to address my friends and colleagues as president of the American Society for Aesthetics, an organization that plays a unique role in a field that is, at once, a major traditional branch of philosophy and also central to disciplines often regarded as remote from philosophy, as well as depending crucially on their contributions.

I will follow the lead of one of my distinguished predecessors in this office, Peter Kivy, who used the occasion of his own presidential address twelve years ago to step back and reflect on the state of the discipline and the nature of aesthetics. ${ }^{1}$

\section{WHAT IS AESTHETICS?}

Aesthetics is a strange field, in some ways a confused one. Yet, among the issues it is charged with treating are some of the most fascinating and profound ones that philosophy has to offer.

I take aesthetics to be largely a branch of philosophy, although with absolutely crucial links to other disciplines. Philosophy as I understand it is not the private preserve of professional philosophers. Art historians, music theorists, and literary scholars frequently engage in philosophy, as do psychologists, cognitive scientists, and linguists. And many informal reflections outside of academic contexts are philosophical in character.

As an institutionally recognized branch of philosophy, aesthetics is very young. At a mere twoand-a-half centuries, in a family whose elders are more like twenty-five, it does not qualify for a midlife identity crisis. Its confusion is that of an adolescent trying to find itself, wondering what to do when it grows up, and, indeed, whether there is a place for it in the adult world. Aesthetics is not the baby of the clan; business ethics and the philosophy of quantum physics are younger. But these are clearly subcategories of traditional, wellestablished areas of philosophy-ethics and philosophy of science - and they inherit much of their identity and sense of purpose from their parents. Aesthetics is not so fortunate. It is related in various important ways to epistemology, metaphysics, philosophy of mind, philosophy of languageindeed it overlaps all of them-but these older relatives are at best aunts and uncles to aesthetics, not parents. Aesthetics must figure out for itself what exactly it is.

Two kinds of issues about the field need to be addressed: What is distinctive about this branch of philosophy, in contrast to others? And what is philosophy? Under the first heading, we will ask what aesthetics is the philosophy of, what domain it is charged with investigating. The second issue concerns what kind of investigation of that domain aesthetics is to undertake, what it is to investigate things philosophically.

$i$. In his Presidential Address for the central division of the American Philosophical Association, Allan Gibbard referred to the question of how to live as the "grand basic question" of ethics. ${ }^{2} \mathrm{He}$ may have had in mind something like this: Most of ethics, most of what now and over the ages is thought of as belonging to that discipline, has some more or less direct connection with how we are to live our lives. Ethical philosophers do much more than attempt to answer this question. They aim to explain and clarify it, they argue about whether it can be answered, and whether answers are "objective" or "subjective," and they examine how people do in fact go about trying to answer it. But it is fair to say that ethics is loosely organized around the question of how to live. This question fixes the 
identity of the field, marks its rough outlines, and gives it a structure. A philosopher can get her or his bearings from anywhere within ethics by ascertaining in which direction this question lies.

Specifying the subject matter of ethics by identifying its GBQ has the advantage of locating its center, as well as its rough boundaries. In fact, once we specify the center, we might prefer thinking of it as not having boundaries at all. We can regard various particular philosophical issues simply as more or less in the province of ethics, as they relate more or less directly to the GBQ.

Epistemology, another ancient branch of philosophy, is similarly organized around the question of what we know or what we can know. The grand basic question of metaphysics is something like: What is there? Notice that all three of these GBQs are ordinary, everyday questions, ones that are likely to bother any reflective person without prompting from professional or self-styled philosophers. Even a person who is not reflective enough ever to ask, "How, in general, should one live one's life?" will certainly ask specifications of this question, "What shall I do now?" Ethics, epistemology, and metaphysics grow naturally out of everyday concerns, out of the "human condition."

What is the grand basic question of aesthetics? As a purported species of "value theory" alongside ethics, one might expect aesthetics to be organized around a normative question corresponding to How to live-perhaps: What to like. This question has indeed exercised some aestheticians. The "Standard of Taste" that David Hume was after can be understood as a way of deciding what we are to like. As Hume put it, such a standard would afford a decision "confirming one sentiment, and condemning another." ${ }^{3}$ Some version of this question - what to like - might come fairly close to qualifying as the GBQ of institutionalized aesthetics in its very early days. But it certainly does not now. Although aestheticians continue to discuss it and issues concerning aesthetic or artistic value, a glance at the pages of The Journal of Aesthetics and Art Criticism reveals how much else they have on their minds, how much of what they think about has no particular connection to these matters. It would be a serious distortion, now, to characterize aesthetics as a species of value theory. Ethics is at most a half-sibling of aesthetics.

If pushed to name a GBQ for their field, some aestheticians will cite "What is art?" This may be the GBQ of the territory Arthur Danto has marked out within the Aesthetics World. Danto, in his words, "regard[s] the matter of furnishing answers to ... questions [such as what difference it makes that Brillo boxes, etc. should be artworks and not mere real things] the central issue in the

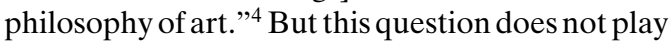
a role in the field as a whole comparable to that of "How shall we live?" in ethics.

"What is art?" is a troubled and seriously contested question, as we all know. Troubled questions are music to philosophers' ears, grist for their mills. The "What is art?" industry certainly is humming along. But the question is problematic in ways that make it ill-suited to define the identity of a major field of philosophy. It is not at all clear that these words-“What is art?"-express anything like a single question, to which competing answers are given, or whether philosophers proposing answers are even engaged in the same debate. Introductory textbooks and encyclopedia articles commonly recount a rather bizarre historical sequence of proposed answers (usually understanding the question to be asking for a definition of the word 'art,' although it does not have to be understood this way). The story goes something like this-with variations, of course: The Greeks defined 'art' in terms of mimesis (representation, imitation), it is said. Then followed formalist definitions, and definitions in terms of expression, and of communication; after that came claims that what makes art art is its institutional status or its historical role, or its place in a symbol system with certain syntactic and semantic properties, or an interpretive theory. ${ }^{5}$

The sheer variety of proposed definitions should give us pause. One cannot help wondering whether there is any sense in which they are attempts to capture the same concept or clarify the same cultural practices, or address the same issue. The historical progression, as commonly recounted, is hardly a dialectical one with each attempt taking what might be right about previous ones and improving on them, or else explaining and accounting for why the previous ones might have seemed right and how they missed out. This is not like the progression of definitions of "knowledge," for instance. Each attempt to define 'art' starts anew, and comes up with something not just different from previous definitions but seemingly unrelated to them. (I am oversimplifying here.) Whatever the explanation for the curiously jagged shape of this history, "What is Art?" will scarcely 
serve as a stable center for a discipline. We should expect a field recognizing this as its GBQ to be rather confused.

In any case, glancing again at recent issues of The Journal of Aesthetics and Art Criticism, it is clear that this does not function as the GBQ of aesthetics as it is currently practiced. Much of what occupies the attention of aestheticians has little if anything to do with any question one might ask by means of the words, 'What is art?' Do readers of literary works empathize with characters? How do formal devices affect readers' emotional responses? What makes for "realism" in literature? In painting or film? Is linear perspective "natural" or "conventional"? What are the mechanisms whereby documentary films alter our beliefs, when they do? In what circumstances are photographs better sources of evidence than pictures of other kinds? Was Plato right to be concerned about insidious moral effects of mimetic poetry? Do fictional characters exist? To what extent might a modern performance of baroque music on period instruments recreate the sounds or the experience of an eighteenth-century performance? These are all immensely fascinating issues. But all can be pursued, and usually are, without worrying about whether or why the works in question qualify as art.

One final contrast between the GBQ of ethics and "What is art?": I mentioned that "How to live?" is a query that arises naturally, inevitably, in ordinary human life. "What is art?" is not, except in rather limited circumstances. Artists, gallery owners, museum curators, critics, and the art public in 1960s and 1970s New York certainly could not avoid it, and it comes up in other contexts as well, but it is irrelevant at best in most of most people's thinking about the arts. Reflective film buffs or music lovers or theater junkies or art connoisseurs may want to figure out why a joke is funny, why and in what way a short story or a musical performance moves them, what they might learn from a documentary and how. But they will surely find the question of what counts as art much less pressing than these, if it occurs to them at all, certainly far less pressing than most of us find the question of how to live. Moreover, it is arguable that no one before the eighteenth century was able even to formulate this question and that it cannot be expressed in some non-Western languages. Aesthetics would not grow out of everyday concerns in the way that ethics does if it were centered on the question, "What is Art?"

The inescapable conclusion is that aesthetics simply does not have a grand basic question. No question or cluster of related questions organizes our field in the way that "How to live" organizes ethics. Georges Santayana implied as much in 1904, when he remarked, in an article in the Philosophical Review: "[T] he word 'aesthetics' is nothing but a loose term lately applied in academic circles to everything that has to do with works of art or with the sense of beauty. ... the group of activities we can call aesthetic is a motley one, created by certain historic and literary accidents." This suggests that the identity of the field is fixed by marking its boundaries, rather than by identifying its center. (Philosophy of science has a similar structure, its domain being the sciences, broadly construed, which it investigates philosophically. I do not think philosophy of science has a grand basic question. Notice that philosophers of science are not overly preoccupied with the question of how 'science' is to be defined; they have lots of other interesting things to think about.) The idea is that the boundaries of aesthetics coincide with the boundaries of the arts and of beauty. Rather than including absolutely everything having to do with art or beauty, however, we might focus on philosophical matters. And some will prefer to substitute the aesthetic for beauty, perhaps in order to include sublimity along with beauty.

So aesthetics is the philosophy of art and beauty, or the philosophy of art and the aesthetic. This sounds comfortingly familiar. It recognizes that we are interested in all manner of issues having to do with paintings, music, theater, literature, film, and anything else that counts as art, not just what makes them art or what works of art have in common-as well as whatever might be philosophically interesting about anything that is aesthetic or beautiful.

This conception of the field, this specification of its boundaries, is hostage to the vagaries of judgments about the extension of the terms 'art' and 'aesthetic,' vagaries that are certainly not limited to fuzziness around the edges. Think of the severe restrictions Leo Tolstoy and Clive Bell put on what is to count as art-vastly different restrictions in the two cases-just a few years before the vast expansion of the class, in the eyes of some artists and critics, to include Marcel Duchamp's Fountain, 
John Cage's 4'33", Andy Warhol's Brillo Boxessome even regarding these as paradigmatic instances of art!

Moreover, aesthetics understood in the spirit of Santayana suffers something of a split personality. There is what is often called nonaesthetic art (Dadaism, the 1960s avant-garde). ${ }^{7}$ And the aesthetic includes much outside the realm of artnot just natural beauty, but also aesthetic qualities in mathematical proofs, scientific theories, chess games, even baseball games and military campaigns, and metaphors used in science or politics as well as in poetry. The test for inclusion within the boundaries of the field of aesthetics appears to be disjunctive: candidates must either involve works of art in some way, or have something to do with the aesthetic (or beauty).

Aesthetics, then, seems hardly to be a unified field of inquiry. What is wrong with not being unified? Nothing, unless an illusion of unity or an unfounded presupposition that there must be such distorts the investigations occurring under this name. Unfortunately, that sometimes happens.

\section{PHILOSOPHY AS THEORY CONSTRUCTION}

What is philosophy? Supposing that we know, more or less, what domain aesthetics is assigned to investigate, what kind of investigation is it to undertake?

Wittgenstein remarked, famously, that philosophy "leaves everything as it is." 8 This contrasts dramatically with an observation his teacher, Bertrand Russell, made in his "Lectures on Logical Atomism": "The point of philosophy is to start with something so simple as not to seem worth stating, and to end with something so paradoxical that no one will believe it." (I am sure Russell meant that if the philosopher has done his or her job well, the "paradoxes" he or she ends up with are ones we should believe, and will believe if we take the arguments for them seriously.)

Wittgenstein's claim would appear to fit some philosophical projects fairly well; others seem more in line with Russell's. I regard most of my own work as, in this respect, more Wittgensteinian in spirit than Russellian, that is, as mostly "leaving things as they are." I do not exclude what I have written about Charles and the Green Slime, or my contention that photographs are transparent. Judging from the incredulous stares these claims have enjoyed, I expect that some of you will disagree, attributing to me paradoxes that Russell might approve. How things are and what it is to leave them that way is not an obvious or straightforward matter, nor is it clear what should count as paradoxical. In any case, I would like to make the aesthetics world safe for Russellian modes of philosophizing as well as Wittgensteinian ones. We need both. And we need to know when one or the other is appropriate, when it is reasonable to insist on "leaving things as they are," and when we should welcome paradoxical-seeming conclusions.

I am especially interested in two related questions about the philosophical enterprise. First, whether and in what sense philosophy is an a priori discipline, as it is often said to be, in contrast to the empirical sciences. We philosophers, aestheticians included, do spend much of our lives lolling around in armchairs. Many have urged us to pay attention to empirical psychology and cognitive science, as well as less formal empirical observations. There has not been enough discussion, especially among aestheticians, of how and why we should, however. Does philosophy aspire to be an empirical science itself, or to contribute to scientific investigations? Is it just science under a different name? If there is something distinctive about the philosophical enterprise, as opposed to empirical ones, what is it? And how, then, might the empirical sciences be relevant to it?

The second question about philosophy that interests me now is what role intuitions, or intuitive judgments, what are sometimes misleadingly called "pretheoretical" intuitions, do or should have in philosophical investigations. We will have to think about what intuitions are, and how they might be related to their close or distant cousins: "common sense," "what we-the person in the street—ordinarily say," and introspective reports.

Intuitions deserve respect. But what kind of respect? It is often assumed that philosophical claims that conflict with intuitions bear a special burden of proof, that counterintuitiveness or unintuitiveness inevitably counts against a theory, even if it is not necessarily fatal. Some philosophers speak of "plain truths" (or what "plainly" or "clearly" is or is not the case), which therefore are not to be questioned, yet not infrequently these seem anything but plain to others. ${ }^{10}$ Some go to great lengths to make their philosophical conclusions accord with what they consider to be ordinary intuitions - taking very seriously the idea 
that philosophy leaves everything as it is. Yet they often need to convince other philosophers that these are "our" intuitions! To the extent that this is controversial, we have to be wary of appeals to intuition in support of philosophical conclusions.

Do empirical scientists have a similar obligation to respect intuition? Is it desirable as far as possible that scientists' results accord with intuition? Certainly, intuition or common sense does and ought to play a role in the generation of hypotheses to be tested, but when it comes to conclusions, should scientists not follow the evidence wherever it leads? If philosophers are required to take intuitions more seriously than this, to treat them as more authoritative than scientists do, we need to ask again why and how philosophers ought to pay attention to science.

"Analytic" philosophers have commonly characterized their endeavor as conceptual analysis. I count myself among those who prefer to understand philosophy as mainly a matter of theory construction. What philosophers do, on this conception, is pretty much what scientists do after the data are in: organizing the data in a perspicuous manner, devising conceptual structures, constructing theories, to clarify and explain the data. ${ }^{11}$ I think that this conception of philosophy applies better than the conceptual analysis one to much historical philosophy, from Plato through Kant, to the "system building" typical of some philosophers in the continental tradition, and, indeed, to much philosophizing by those who claim to be engaged in conceptual analysis. Not everything philosophers do is happily regarded as theory construction, however. Normative and applied ethics are not; I take theories to be purported accounts of how things are, not of how things should $b e$. The same goes for "normative aesthetics," I should think, although the line between normative aesthetics and (shall we call it?) meta-aesthetics is even fuzzier than that between normative and meta-ethics.

I should say right off that I understand 'theory' as a count noun, not a mass noun. Theory is not a kind of glop that one spreads over a subject matter-probably obscuring it-in a process some call theorizing the subject matter. My interest is in particular theories, designed to explain and help us understand a body of data.

I will say as little as I possibly can about what theories are, hoping to avoid unnecessary entanglements. Let us just observe that: (1) theories are to be distinguished from the data on which they are based and that they are supposed to explain, and are subject to confirmation or disconfirmation by the data. (What counts as data for a given theory may be, however, facts understood in terms of lower-level theories.) (2) Data underdetermine theory, that is, different theories may accommodate the same data. So choosing among competing theories is not always a matter of discovering evidence that supports one and conflicts with another; choices must be made on the basis of simplicity or elegance or perspicuousness or explanatory power-whatever exactly these amount to. I will not try to say what they do amount to, except to observe that (3) theories involve, or consist partly in, a taxonomy, a representation of similarities and differences among items described by the data. Understanding things consists, in part at least, of noticing, appreciating, similarities and differences. A change in one's theory usually involves recognizing or emphasizing new similarities and differences. These three observations are boringly obvious, I hope, and too vague to be controversial.

Theory construction is not the exclusive province of scientists, philosophers, and other specialists. We all do it all the time. The conceptual schemes embedded in natural languages amount to theories, folk theories, which have evolved over centuries or millennia and continue to change, undergoing revision as humans struggle to understand their world, and as their world changes. If philosophy is theory construction and theory construction is such a widespread activity, is there anything special or distinctive about the philosophical enterprise? Do philosophers construct theories of a special kind, philosophical ones, differing fundamentally from scientific theories and the various folk theories? I don't think so. Nor do I think philosophers are concerned with a special subject matter, about which they construct theories. Adherents of the conceptual analysis view of philosophy might say that philosophers are especially or uniquely interested in our concepts. But why should the investigation of our concepts not be a job for empirical psychology?

What is (somewhat) distinctive about philosophy is the role philosophers play in the construction of theories. They specialize in devising theories, or choosing among alternative theories, after the data are in, as I mentioned. Given a body of data already available, they reflect on how best to organize or interpret it. They also propose 
hypotheses when the evidence available is insufficient or when it is unclear what evidence would be relevant; they suggest theories that might or might not turn out to be right. The data philosophers organize include, or should include, results of scientific experimentation and observation. Like hyenas feeding on carrion, philosophers appropriate data collected by others. But they traditionally have concentrated on devising theories to explain much that is common knowledge, everyday facts of which all of us are aware (or think we are), although we may need to be reminded of them, or what is or seems to be open to introspection. (If you are concerned that this does not give philosophers a very substantial or significant role, think of Kant's first Critique.)

Hume took it to be obvious to everyone that "there is a great variety of Taste," and evident upon reflection that there is even more variety than there seems to be, when you subtract merely verbal agreement. ${ }^{12}$ Hume expected his readers to agree, without leaving their armchairs, that Milton is better than Ogilby. ${ }^{13}$ Clive Bell purported to direct our attention to a kind of experience he thought "sensitive" people are or can be aware of, which he took as data for his (rather minimal) theory construction. ${ }^{14}$

Some empirical facts that can serve as data for theory construction are perfectly obvious but only when someone points them out. One example: in low light conditions, when it is nearly dark, we see in black and white, or rather in shades of gray; we see shapes and contrasts of illumination, but not hues. This fact of experience, obvious once we notice it, might help us to understand the experience of black-and-white pictures: photographs, drawings, prints. One might have expected that blackand-white photographs inevitably depict things as poorly illuminated. This is certainly not so. But it does seem to me that black-and-white pictures, in contrast to full-color ones, tend not to depict brightly illuminated scenes very vividly.

What seems to be common knowledge, everyday facts about which philosophers spin theories, are sometimes just mistakes. What are taken as data in one philosophical discussion may, in another, be part of a controversial theory with viable competitors, or worse. And "common knowledge," "plain truths," often evaporate embarrassingly when they are empirically tested. When an aesthetician declares, from an armchair, that every language has a word for beauty, or a cog- nate of the English word 'beauty,' we should be suspicious. ${ }^{15}$

Nevertheless, there is a body of very ordinary knowledge, gleaned from everyone's everyday experience of the world, which seems pretty secure, and that constitutes a large part of the data that philosophers' theories are designed to illuminate. I sometimes mention the experience of scratching on a blackboard when I want to disabuse people of the idea that taste, or what people like, is a radically conventional matter, that our likes and dislikes are all "learned" responses. It seems obvious to mefamous last words - that cringing at the sound of scratching on a blackboard is about as hardwired as any response is. How do I know? Well, I am convinced, and I am convinced that others will agree. Maybe I shouldn't be.

Something of an a priori-or quasi-a prioricharacter of the philosophical enterprise is now evident. Rather than running experiments or doing surveys or recording observations, philosophers typically reflect on what all or most of us already know. This they do in armchairs. Armchairs are fine, also, for collecting data by reminding ourselves of what we already know, and for reading up on the data scientists and other researchers gather. The theories philosophers construct are empirical in the sense that they are based on and aim to explain empirical data, but constructing them once the data are in requires no additional empirical investigation. Deciding which of several competing theories best explains a given body of data, or a body of possible or hypothetical data-deciding this on the basis of simplicity or elegance or perspicuousness or explanatory power-would seem to be about as a priori a task as there is. And so is judging how well a particular theory explains a body of data.

\section{FOLK THEORIES}

Folk theories embedded in our language are also attempts to understand facts, organize data, that are common knowledge. Since we philosophers are in this business as well, we should pay attention. Folk theories are likely to have evolved because they have some merit, and most have served well for many purposes. This is one reason philosophers should respect "intuitions" ("common sense," "what we ordinarily say"), for these are no doubt reflections of folk theories. 
Concepts of art are part of an evolving folk theory that takes a wide variety of activities, interests, experiences, and objects as data. It is generally accepted that the "modern" concept of art took shape in the eighteenth century in Europe. ${ }^{16}$ That was not the beginning of art, of course. The ancients created and appreciated art, and so did and do people in various non-Western cultures who arguably lack our concept. The concept is not part of a social or institutional framework required for the production and appreciation of art, not all art anyway, but a tool for making sense of the arts and their institutional settings; it is part of a folk theory for understanding them.

Some will regard the jelling of the concept in eighteenth-century Europe as a significant conceptual breakthrough, an improvement in our folk theories. We are better able to understand the nature and functions of painting, poetry, music, and architecture, one might supposeGreek monuments, Gothic cathedrals, Japanese haiku, Javanese shadow puppet theater, Chinese scroll painting, Yoruban sculpture, the creations of Proust, Picasso, and Beethoven-we are better able to understand them now that we comprehend them all to be instances of art. The classification itself, simply seeing all these things as similar or as serving similar ends, may appear to constitute a significant advance in understanding. Recognizing this similarity does not, of course, prevent us from recognizing enormous differences among the species of the genus.

Aestheticians may seek to clarify and deepen the understanding provided by our folk theory by spelling out what the various works of art have in common, what it is that qualifies them as art in the "modern" sense, by offering a definition of 'art' that captures this folk concept. This is conceptual analysis, I take it, the project of clarifying and articulating concepts that constitute folk theories. (Some recent research suggests that our ordinary concepts, those that make up folk theories, may be in prototype form, rather than the form of necessary and sufficient conditions. ${ }^{17}$ If this is right, then necessary and sufficient condition definitions offered by the conceptual analyst will be a kind of translation of the folk concepts. Such translations may have certain advantages, akin to those of information in digital as opposed to analogue form.)

The philosopher who aims to construct the best theory or theories possible for understanding and explaining a body of data is well advised to be- gin with conceptual analysis, to look carefully at the candidate theories folk wisdom provides. They are not gospel, but they merit the kind of respect we accord testimony from a source that has some credibility.

Credible testimony can be wrong, and all theories are subject to revision. Conceptual analysis reveals plausible candidate theories worthy of consideration, but it also puts us in a position to evaluate them, to think about how they might be improved, even to consider wholesale replacements.

Who are we to second-guess centuries or millennia of conceptual development, some will ask. New evidence may demand new or revised theories, to be sure. But insofar as we philosophers are working with the same data available to the folk, with what is common knowledge, should we not limit ourselves to clarifying and articulating folk theories, and then just accept them? Is it not presumptuous to imagine that we can do better? This is one way of defending Wittgenstein's plea to "leave things as they are" and to avoid Russellian paradox mongering.

One answer is that what counts as a good theory, or a theory that is better than others, often depends on one's purposes. A theory serving culinary purposes and a biological theory will classify plants and parts of plants differently. The purposes of philosophers and those of the folk might not coincide, so folk-wise theories may not be best from a philosopher's point of view. What matters to the folk is, probably, the effectiveness of theories in guiding action. Philosophers are likely to be more interested in achieving understanding for its own sake. The folk concept of fiction (as opposed to nonfiction) serves a practical purpose, insofar as people largely agree on its application. It enables us to find books in libraries and bookstores and catalogues. But it does not do well at all in helping us to understand the nature of the books it classifies; it is a mess. It embodies confusions between notions of truth and falsity, intended or aimed for or purported truth and falsity, assertion, informativeness, intended informativeness, inducement to imagine, or prescriptions to imagine, and so on. ${ }^{18}$

A second answer to the challenge that it is presumptuous for philosophers to try to improve on folk theories concerns the manner in which folk theories develop.

Biological evolution works bit by bit, repeatedly making local modifications in existing 
structures to accommodate new conditions or needs or circumstances. (This does not mean that the pace of evolution is always slow.) It does not start from scratch, designing from the ground up the ideally efficient and economical and successful solution to a given set of problems and interests. The results, after many millennia of trial and error, are incredibly successful, but they are never ideally efficient. Organisms are burdened with vestigial organs and processes (for example, the human appendix) and awkward designs, which waste energy or resources, and sometimes break down and cause problems.

The development of folk theories proceeds by bit-by-bit modifications as well, to accommodate new or newly noticed data, additions to our stock of common knowledge or newly noticed relations among the data, and new purposes; perhaps also to take advantage of increased brain power or leisure for reflection or new conceptual tools such as language or the printing press. The theories that result are remarkably effective, especially in guiding action in the real world, but they, too, are unlikely to be ideally elegant or economical. Philosophers are in a position, sometimes, to construct theories more nearly from the ground up, and can eliminate vestigial gears and pulleys and other awkwardness. So philosophers may have good reason to revise or replace folk theories, even without introducing new data.

Efficiency, economy, and simplicity are often instrumentally valuable in biological organisms. They minimize what might go wrong (although redundancies are sometimes desirable at the expense of economy). Fixes or backup systems can evolve to repair damage or compensate for insufficiencies, but these are also subject to failure, and may require more energy or strength or size or brain capacity. The same is true of folk theories, insofar as their function is to guide action and to help the folk survive. But efficiency, economy, and simplicity are intrinsic values of theories insofar as they serve, not primarily to guide action, but to foster understanding. And it is understanding, I assume (whatever that is), that the philosophical aesthetician is mainly interested in.

Nelson Goodman is notorious for trashing folk theories and replacing them with his own. In the preface to Languages of Art he writes: "the reader must be prepared to find his convictions and his common sense - that repository of ancient erroroften outraged by what he finds here."19 Many find outrageous Goodman's insistence that a single wrong note disqualifies a musical performance as a performance of a given musical work. Intuitions are affronted if we suppose that he is attempting to articulate the folk concept. Yes, it is plainly false that a performance cannot contain a single wrong note, given the folk concept of performance. But Goodman does not claim otherwise. He contends that the ordinary, folk concept of musical performance is incoherent-he may be right, although he did not do any serious conceptual analysis - and he replaces it with another one. What is wrong with this? He could have made his proposal seem innocuous simply by introducing new terminology, a technical notion of letterperfect performance, on which it is analytic that a letter-perfect performance cannot tolerate a single wrong note, and substituted this new notion for the folk one. ${ }^{20}$ I do not buy Goodman's proposal even so, for reasons I will mention shortly.

Much has been said about the viability of the folk concept or concepts of art. I am inclined to regard its development—not so much perhaps its initial appearance in the eighteenth century as the form or forms it has taken since then-less as a conceptual breakthrough in our understanding of paintings, sculpture, music, and architecture, than as a puzzling turn in the evolution of our folk theories that calls for historical or sociological explanation. I will not defend this claim now, but it cannot be ruled out without a hearing. ${ }^{21}$

$i$. So much for the case-a pretty obvious onefor not being easily satisfied leaving things as they are, for regarding folk theories and folk concepts with a skeptical eye, and being prepared to accept something that seems paradoxical at first. This is not the whole story.

Folk theories and folk concepts are sometimes objects of philosophers' investigations, part of the data on which philosophers' theories are based. This is so when philosophers examine cultural practices and institutions and the thoughts and activities of the folk who participate in them, for in participating the folk deploy their theories and concepts. Aesthetics investigates the experiences and attitudes and activities of human beings and their cultural institutions, not just painted canvases, sounds emanating from sound-making devices, and inscriptions of words on the pages of books. So part of the job of aestheticians is to get a clear picture of the actual folk theories 
and concepts that our experiences and attitudes and activities involve. This is conceptual analysis more or less for its own sake, not just to uncover candidate theories for consideration and evaluation in competition with other theories.

There need be no presumption that the folk theories we examine are any good, or that intuitive or common-sense judgments reflecting them are true or plausible or illuminating. But we need to get them right, however confused or awkward or inelegant or burdened by vestigialities they may be. If we are to understand the thoughts and actions of the folk, we must characterize accurately the theories and concepts with which they are working, all warts included.

We have distinguished two very different roles that intuitive or common-sense judgments reflective of folk theories and concepts may have in the philosophical enterprise. They will be treated as hypotheses, candidates for acceptance by the philosopher but subject to rejection or modification, when the philosopher is interested in explaining the same body of data that the folk theory aims to explain. When what the philosopher is interested in understanding includes the folk and their theories and concepts, the fact that the folk have such and such intuitions constitutes data itself that the philosopher's theory must accommodate..$^{22}$

Some think it is acceptable or desirable for philosophers to clean up ordinary (folk) concepts around the edges, to refine them in certain ways, removing confusions or messiness, while resisting any large modifications or replacements. This attitude does not make much sense. If our project is one of investigating folk concepts, we should not be cleaning them up; doing so amounts to falsifying the data with which we are working (although, like rounding off statistical data, the falsification does not always matter much). If, on the other hand, our project is to understand what a folk theory aims to understand, to find the best theory we can, possibly in competition with it, we must not decide in advance to rule out major revisions of it or replacement of it with another.

There is plenty of room for confusion between these two ways of treating intuitive and commonsense judgments and the folk theories they reflect, and there has been a lot of confusion in the literature-especially, it seems to me, in philosophical work billed as "conceptual analysis." A principle of charity may play a role in investigations of folk concepts. Other things being equal, we may prefer to attribute to the folk a better theory rather than a worse one. If so, we will need to think about what would be the best theory, of whatever the folk theory is a theory of, in order to decide what the folk theory is. But this does not entail any obligation to accept the folk theory.

Let us return to Goodman's "outrageous" proposal about musical performances. I have argued (very approximately) that the experience of music involves hearing sounds not just as sounds, but as a rendition of a given piece. ${ }^{23}$ Something like the folk notion of a musical work, whatever its inadequacies, informs listeners' auditory experiences. Wrong notes sound like wrong notes, not like correct notes in a different piece. In hearing them as wrong, we have to be hearing the performance as a performance of one piece rather than another-and this, of course, in the folk sense of "performance of," not Goodman's. To understand listeners' experiences, then, we need to take into account the folk notion of musical performances. The problem with Goodman's theory is that it completely abandons this folk notion, and the concept with which he replaces it does nothing to illuminate listeners' experiences.

ii. Conceptual analysis-investigating our folk theories and concepts-is a matter of constructing theories about them, theories about our folk theories. This is true whether our interest is in the folk theories themselves and their role in the folks' lives, or in the folk theories as candidates for evaluation.

No one supposes that folk theories and concepts, one's own theories and concepts, are straightforwardly open to introspection. The usual procedure is to ask ourselves "what we would say" in various actual or hypothetical circumstances, and piece together from the answers definitions, which supposedly correspond to our folk concepts. Even if we get it right-about what we would say when-extracting the appropriate definitions is anything but mechanical or simple. It is heavyduty theory construction involving inferences to the best explanation from a big variety of data. We construct a theory about what our own folk concepts and folk theories are. We must decide when to regard a word as having different senses in its various applications, hence presumably corresponding to more than one concept, for instance. We must decide when we folk use words in a nonserious or nonliteral manner, or in pretense or 
with tongue in cheek-when we are applying a predicate to something that does not really fall under the corresponding concept. None of this can be simply read off from what we would say when.

Frank Sibley argues that, although "common sense" has it that the Mona Lisa is a painting-that our existing notion of works of visual art like the Mona Lisa is such that they are paintings, physical objects-our "practices" indicate equally strongly that the Mona Lisa is an appearance type. Either our inherited (folk) concept of visual artworks is confused, he claims, or we actually have two of them. ${ }^{24}$ What he means by "common sense" is the received theory about our folk concept of works of visual art (a folk theory about a folk theory). This common-sense theory is mistaken, Sibley thinks, and needs to be replaced by a better one, a better theory about the nature of our folk concept of works of visual art. And this better theory has it that the folk concept is seriously confused. We may or may not agree with Sibley about this particular case, but we must agree that "[c]ertainly the common-sense view even about common concepts is often naïve, superficial, and wide of the mark." 25

I cannot resist mentioning one other example. Is the folk concept of "seeing" such that when I look at a photograph of a person I am seeing the person? When Salmon Rushdie, speaking of the film The Wizard of $\mathrm{Oz}$, remarked: "I found myself staring at an old color photograph of the Scarecrow, the Tin Man and Dorothy, posing in a forest set, surrounded by autumn leaves; and realized that I was not looking at the [movie] stars at all, but at their stunt doubles, their stand-ins. ${ }^{" 26}$ Did he mean this literally, that he really was seeing the stunt doubles via the photograph, or was he speaking in pretense, with tongue in cheek? The answer is anything but obvious. And do not look to Rushdie for an authoritative introspective report. Neither the difference between literal and nonliteral uses of language, nor that between single and multiple senses of words, is straightforwardly open to introspection. For one thing, the ordinary speaker need have no concept of these distinctions, even if he or she is perfectly fluent in the language. The notion of literalness and that of different senses of words belong to fairly technical theories about our language, theories one need not master in order to use the language - any more than one must have a concept of art in order to make and appreciate art. Moreover, the theories to which these notions belong are subject to revision. ${ }^{27}$

Those who think it is counterintuitive that we see through photographs presumably mean that given the ordinary, folk notion of "see," this is not so. They are on spongy ground even on this point. And my transparency claim is not a claim about the folk notion of seeing.

\section{AESTHETICS AND THEORY CONSTRUCTION}

In his presidential address, Peter Kivy recommended a moratorium on "theorizing in the grand manner." He proposed focusing on differences rather than similarities, and advised aestheticians to acquire knowledge of and expertise in particular arts. "[P]rogress in the philosophy of art in the immediate future is to be made not by theorizing in the grand manner," he said, "but by careful and imaginative philosophical scrutiny of the individual arts and their individual problems." "We can no longer hover above our subject matter like Gods from machines, bestowing theory upon a practice in sublime and sometimes even boastful ignorance of what takes place in the dirt and mess of the workshop." 28

Something is out of kilter here. Certainly, we aestheticians should mix it up with the dirt and mess of the workshop, pay close attention to the particular arts, indeed to particular works of art and particular experiences of them, as well as creative activities like telling stories and playing the oboe. All this is exactly what we are seeking to understand. And yes, we should be sensitive to differences, differences among the arts and also differences between instances of a given art. But why must we choose between attending to particulars and developing grand theories? Why would we want to choose, or even to move one of them temporarily to a back burner? Theories are supposed to illuminate particulars, to explain and help us understand the data on which they are based. That is what theories are for, what good ones do. Moreover, the illumination good theories achieve, grand ones included, consists in bringing out differences no less than similarities. If we want to investigate particulars, we had better be constructing theories about them.

Kivy is concerned specifically with just one sort of grand theory. He "quarrel[s] with the task ... of stating what it is to be "art." "29 I quarrel with 
it also. Discussions of what art is do, too often, hover far above and out of sight of the fascinating particulars of what goes on in concert halls, jazz clubs, museums, and the spaces of street theater performances and public sculpture. But it is not so much the distance of "What is art?" from these particulars as its direction from them that inhibits the view. The grandeur of the theorizing is not the problem. In fact, the bigger the theory, the more grand it is, other things being equal, the better it will explain the particulars on which it is based. The trouble is with this theory, or theories of this kind-theories focusing on what it is to be artnot with grand theorizing as such. Aestheticians have, much of the time, been talking up the wrong theory. As long as we think of our field as aesthet$i c s$, it will be easy to suppose that the only space our theories have to expand in is that of some preconceived realm of art and/or the aesthetic, and that a sufficiently grand theory will be one that tells us what art or the aesthetic is and asserts generalizations about this realm. Once we realize that theories can expand in different directions, we will not have to assume that the only alternative to this kind of grand theorizing is simply to stare hard at the particulars, or to devise small-scale theories concerning particular arts.

Grand theories do point to similarities. Grandeur consists in including lots of things under a single umbrella, highlighting what is in common among a wide array of instances. But noting similarities is often the key to understanding differences. And some differences are not apparent except against the background of similarities. Once we recognize the effect of gravity on both falling apples and circling planets, we can explain their very different motions by noting the operation of centrifugal force in one case but not the other. Sometimes we can understand what appears to be a qualitative difference as a difference of degree, along one or more dimensions. The various hues are not just different from one another, but are arranged along a spectrum. Timbres, tone colors, amount to differences in the relative strength of various overtones. Some qualitative differences are not reducible to, but results of, quantitative differences. The different viscosities of ice, steam, and liquid water are due to differences in the degree of kinetic energy of their molecules.

What is unsatisfying is to end up with just a lot of unexplained differences-sui generis particulars, or narrow kinds of things regarded as sui generis-about which we can say only that each is as it is. (Think of the "peculiar experience" that Clive Bell thought works of art provoke in "sensitive observers," or the experience of seeing in if we do no more than point to it.) One does not explain anything by declaring that it is just different; that is simply declaring defeat. We cannot be certain that there always will be more to say than this, and we should be ever wary of artificially forcing uncooperative data into a larger theoretical structure. But surprising similarities that help make sense of differences, grander theories than we expect, are not infrequently to be discovered.

As so often happens, we can learn from fictional characters. Consider Ireneo Funes, who resides in Jorge Luis Borges's story "Funes the Memorias." After being thrown by a horse and paralyzed, Funes had an incredible capacity to perceive and remember details. "The present was almost intolerable in its richness and sharpness, as were his most distant and trivial memories." "Lying on his back on his cot in the shadows, [he] could imagine every crevice and every molding in the sharply defined houses surrounding him." But, Borges's narrator observes:

He was ... almost incapable of ideas of a general, Platonic sort. Not only was it difficult for him to comprehend that the generic symbol dog embraces so many unlike individuals of diverse size and form; it bothered him that the dog at three fourteen (seen from the side) should have the same name as the dog at three fifteen (seen from the front). His own face in the mirror, his own hands, surprised him every time he saw them.... He was the solitary and lucid spectator of a multiform, instantaneous and almost intolerably precise world.

I suspect ... that he was not very capable of thought. To think is to forget differences, generalize, make abstractions. In the teeming world of Funes, there were only details, almost immediate in their presence. ... Ireneo Funes died in 1889, of congestion of the lungs. ${ }^{30}$

$i$. Let us look at some of the specific differences that Kivy highlights. He distinguishes (absolute) music sharply from the "contentful" arts, such as painting and literature. "[T]heorizing about absolute music in the grand manner, with a view to providing it a place in Kristeller's 'Modern System of the Arts,' is a futile enterprise," he says. "Absolute music is what it is; and what it is is very different, in crucial respects, from the visual and literary arts." 31 
He does connect music with decorative visual designs, however, as Eduard Hanslick did also, characterizing music as "an art of pure sonic design." 32 I think there is something to this comparison, but it is not easy to say what. Kivy thinks both are nonrepresentational; there is no aboutness about either of them. But this negative observation does not do much to account for the similarity, even if it is right. There is also no aboutness about most rocks and trees and mugs of beer; at least I expect that Kivy would agree. Music and visual designs are very different, also. One especially striking difference is evident in the fact that people tap their feet to music, and sometimes dance to it, but not to decorative visual designs, not even to moving ones, screen savers, for instance. ${ }^{33}$ But hugely important and enormously salient differences can coexist with equally important and salient similarities.

Apparently, Kivy recognizes a similarity between the visual and the literary arts, both being "contentful." But he emphasizes differences instead. "[T]he experience of reading a novel is so different from that of seeing a representational painting, or attending a dramatic representation, that it is in a deep way false and misleading to put both kinds of thing in the same category, [and] call it 'representation."'34

What we call the category is not the issue, of course. Kivy uses the term 'representation' more narrowly than some do, corresponding approximately to what I call depictive representation. What is at issue is whether it is theoretically illuminating to recognize a broad category including novels and stories as well as representational paintings and theatrical performances, with various species and subspecies. Again, that paintings and novels, or our experiences of them, are hugely different does not mean that they are not also hugely and importantly similar.

As you may know, I recognize a very broad category of "representations," comprising novels and representational paintings and theatrical performances and much else besides (though not everything Kivy would describe as contentful). All representations, in my sense, involve, in a certain way, an imaginative activity that I call make-believe; all possess the function of serving as props in games of make-believe. Intuitively, we can think of them as establishing fictional worlds. I do not for a minute deny or ignore or deemphasize the differences among the members of this large class.
Much to the contrary, recognizing the commonality highlights many differences, big and small, and provides vast resources for understanding them. We can now distinguish between different kinds of make-believe, different varieties of imaginings and imaginative experiences (de re, de dicto, de $s e$, differences of vivacity, explicitness, deliberateness), different purposes for which we imagine or engage in make-believe, different (real) objects imagined about, different rules or conventions or inducements to imagine this or that. Paintings are distinguished from novels primarily by the fact that they and other pictures are props in visual games of make-believe.

It turned out, much to my surprise, that much music counts as representational in my sense. Rather than hanging on for dear life to the supposed "plain truth" that (absolute) music does not belong with painting and literature, we ought to acknowledge what commonalities there are, and then look to understand the differences. Music qualifies because (very roughly) of the richly imaginative nature of musical experiences-when, for instance, we hear one musical idea or event growing out of another, or interrupting or interfering with another, or one preparing the way for another. Listening to a cantabile passage on the piano or violin, we are likely to imagine (implicitly) hearing a human voice. Certainly, there are differences-more fundamental differences than those between experiences of literary works and visual depictions. They are, to a large extent, differences in the kinds of imaginings in which appreciators engage and how they are involved in their overall experiences, differences that would not be apparent if we just declare music to be what it is, without recognizing the similarities. ${ }^{35}$

My motivation in recognizing the broad category of representations is not to validate an eighteenth-century folk conception of $a r t$, defined in terms of mimesis, or a twentieth-century one, or to shoehorn music in with the other arts. I do not claim that make-believe or fiction is involved in all the arts, and certainly not that it is always or ever what is most important. Make-believe, in various forms, occurs just as importantly and extensively outside the arts as inside. I and others have made various suggestions about where it is to be found. Some of them are controversial but many are not. Make-believe (or a close relative) has been positively identified or strongly suspected in scientific and philosophical thought 
experiments, in metaphor, irony, and quotation, in empathic experiences and simulation as a means of understanding other people, and in counterfactual reasoning, not to mention children's games. One example that has not been much discussed is sports. It will not come as much of a surprise that an element of make-believe is to be found in the realm of sports. What is especially interesting and illuminating, it seems to me, are differences: the differences between, for instance, the experiences of sports fans and those of theatergoers, once certain similarities are noted. But this is a topic for another occasion. ${ }^{36}$

There is nothing especially artistic or aesthetic about make-believe or fiction or representation, as such. If representation in my broad sense were to shoehorn music into the class of fine arts, it would shoehorn in a lot more as well. John Cage would be delighted, but many of us would not. There is no reason why the investigation of fiction should be a job especially for aesthetics. The theory I propose is not a grand theory of art, but a theory that straddles most any way of construing the art/nonart boundary.

\section{v. CONCLUSION}

You may or may not be disposed favorably toward my theory of representation, either as a whole or in any of its details. My main interest here is methodological. The methodological morals of my observations can be summed up as advice that we not take the folk concept of art too seriously in our endeavor to make sense of stories, paintings, music, architecture, sculpture, and so forth, and the roles they play in our lives. This advice has three parts.

1. First, we should not take this folk concept or any particular refinement of it automatically as a pillar of a theory we expect to endorse. We should treat the folk theory it belongs to as just one candidate to be considered among others.

2. We must recognize that people in various cultures have and use one or another concept of art, that it is an element in some folk theories (although we must take care not to attribute concepts of art to folk who do not possess them). The philosophical theories we construct will have to accommodate this fact, insofar as we are interested in understanding these cultures and their folk theories or the complicated historical development of concepts of art. So we need to represent as accurately as possible the character of the folk concepts. It may be helpful to think ourselves into the state of mind of one who accepts a folk theory, to regard the theory from the inside, and we may find ourselves "speaking with the vulgar." It may be helpful to empathize with the folk, in order to understand them. But this does not require us to endorse the folk theory. Any endorsement must be based on the theory's merits. Empathizing with the folk should not be at all difficult, since the philosophers and the folk are often the very same people. It is my own folk theory with which I shall empathize. But the ease with which I empathize can encourage unwitting, inappropriate endorsement, or make it seem, even to myself, that I endorse something on which I intend to reserve judgment.

3. My final methodological recommendation looks back to our earlier observations about the peculiarities of the subject matter of the discipline of aesthetics, the domain it is assigned to investigate. We should not allow the concept of art, or the fact that we bill ourselves as "philosophers of art," to determine the scope of our investigation. We should not allow it either to restrict artificially the data we take into account in constructing a theory, or to trick us into including data that do not belong. We must not suppose that the traditional boundaries of the field of aesthetics, defined partly by the folk notion of art, will demarcate a body of data on which we can focus productively, a body of data we can expect a single theory to explain. Such suppositions are dangerous, and the apparent arbitrariness of the boundaries, as well as the absence of a grand basic question, should make us especially wary.

My advice is to start from the ground up, with careful attention to works of art that interest us and to whatever else turns out, on examination, to bear significant similarities to any of them, and let our theories develop as they will. We should go for grandeur when we can, when the data we come up with and theoretical considerations support it. But the shape our theory or theories take in the end, as well as their size, what they end up being 
theories of, must not be decided in advance. Choices of subject matter are not theoretically neutral; they amount to guesses about what shaped theory will be viable, guesses that may or may not turn out to be right. The scope of an investigation must not be dictated by the boundaries of our, or anyone's, folk concept of art (or any folk concept of the aesthetic), or by the traditional shape or size of an academic discipline.

If the theory we come up with does not exactly count as a theory of aesthetics, or a theory that fits comfortably within the discipline of aesthetics, fine. What matters is whether it successfully illuminates Gothic cathedrals or Romantic poetry or medieval plainsong or Javanese shadow puppet theater or film documentaries or Chinese scroll painting or Monet's Water Lillies or Tolstoy's War and Peace or poetry slams or jazz improvisation or political campaigns or baseball games or magic shows or circus acts or sales demonstrationswhat matters is whether it successfully illuminates some combination of these and/or anything else we might be interested in-the more of them the better.

It's that darn concept of art that has made it so hard to understand art-and lots of other things as well. ${ }^{37}$

\section{KENDALL WALTON}

University of Michigan

Department of Philosophy

Ann Arbor, Michigan 48109

INTERNET: klwalton@umich.edu

1. Peter Kivy, "Differences," The Journal of Aesthetics and Art Criticism 51 (1993): 123-132.

2. Allan Gibbard, "The Reasons of a Living Being," Proceedings and Addresses of the American Philosophical Association 76 (2002): 49-60, see p. 54. 'The grand basic question' will hereafter be 'GBQ.'

3. David Hume, "Of the Standard of Taste," in Essays Moral, Political and Literary, rev. ed., ed. Eugene F. Miller (Indianapolis: Liberty Classics, 1986), p. 229.

4. Arthur Danto, "Moving Pictures," Quarterly Review of Film Studies 2 (1979): 1-24, see p. 7.

5. See, for example, Annette Barnes, "Definition of Art," in Encyclopedia of Aesthetics, vol. 1 (Oxford University Press, 1998), pp. 511-513. Also Kivy, "Differences," p. 126.

6. George Santayana, "What Is Aesthetics?" Encyclopedia of Aesthetics (1904). Reprinted in Obiter Scripta: Lectures, Essays and Reviews, ed. Justus Buchler and Benjamin Schwartz (New York: Charles Scribner's Sons, 1936), p. 32.

7. Timothy Binkley, "Piece: Contra Aesthetics," The Journal of Aesthetics and Art Criticism 35 (1977): 265-277.
8. "Philosophy may in no way interfere with the actual use of language; it can in the end only describe it.... It leaves everything as it is." Ludwig Wittgenstein, Philosophical Investigations, 3rd ed. (New York: Macmillan, 1958), § 124.

9. Bertrand Russell, "The Philosophy of Logical Atomism," in Logic and Knowledge, ed. Robert Charles Marsh (London: George Allen \& Unwin Ltd., 1956), p. 193.

10. A couple of random examples: Nelson Goodman, Languages of Art: An Approach to a Theory of Symbols (Indianapolis: Bobbs Merrill, 1968), p. 245; Kivy, "Differences," p. 127.

11. Data gathering and theory construction are not sharply separate in practice, of course, nor does the first always precede the second. A budding theory makes predictions, indicating where to look for further data.

12. "The great variety of Taste, as well as of opinion, which prevails in the world, is too obvious not to have fallen under every one's observation." Hume, "Of the Standard of Taste," p. 226.

13. Hume, "Of the Standard of Taste," pp. 226-227, 230 231

14. Clive Bell, Art (New York: Putnam,Capricorn, [1914] 1958).

15. "Beauty is a distinctive and a timeless concept. The term itself has cognates in every language, and in every language it plays a role in pretheoretical informal talk." Mary Mothersill, "Beauty and the Critic's Judgment: Remapping Aesthetics," in The Blackwell Guide to Aesthetics, ed. Peter Kivy (Malden, MA: Blackwell, 2004), p. 157.

16. Paul Oskar Kristeller, "The Modern System of the Arts," in his Renaissance Thought and the Arts (Princeton University Press, 1990).

17. Compare William Ramsey, "Prototypes and Conceptual Analysis," in Rethinking Intuition: The Psychology of Intuition and Its Role in Philosophical Inquiry, ed. Michael DePaul and William Ramsey (Lanham: Rowman \& Littlefield, 1998), pp. 161-178; Stephen Laurence and Eric Margolis, "Concepts and Cognitive Science," in Concepts: Core Readings, ed. Eric Margolis and Stephen Laurence (MIT Press, 1999), pp. 1-81; Eleanor Rosch and Carolyn B. Mervis, "Family Resemblances: Studies in the Internal Structure of Categories," in Rethinking Intuition, pp. 17-44.

18. Compare Kendall Walton, Mimesis as Make-Believe: On the Foundations of the Representational Arts (Harvard University Press, 1990), ch. 2.

19. Nelson Goodman, Languages of Art: An Approach to a Theory of Symbols (Indianapolis: Bobbs Merrill, 1968), p. xii.

20. In redefining 'performance of,' rather than coining a new term Goodman is following the usual procedure whereby the folk mark changes in their theories. Think of the change that occurred when people "realized" that there are mental "diseases" as well as physical ones.

21. See my review of George Dickie's Art and the Aesthetic: An Institutional Analysis, in Philosophical Review 86 (1977): 97-101; and my review of the Encyclopedia of Aesthetics, "Is 'What Is Art?' Really the Question?" Times Literary Supplement, September 29, 2000: 8-9.

22. Compare Alison Gopnick and Eric Schwitzgebel's discussion of "intuitions as hypotheses" and "intuitions as evidence." "Whose Concepts Are They, Anyway?: The Role of Philosophical Intuition in Empirical Psychology," in Rethinking Intuition, pp. 78-81. 
23. Kendall Walton, "The Presentation and Portrayal of Sound Patterns," in Human Agency: Language, Duty, and Value, ed. Jonathan Dancy, J. M. E. Moravcsik, and C. C. W. Taylor (Stanford University Press, 1988), pp. 237-257.

24. Frank Sibley, "Why the Mona Lisa May Not be a Painting," in Approach to Aesthetics: Collected Papers on Aesthetics, ed. John Benson, Betty Redfern, and Jeremy Roxbee Cox (Oxford University Press, 2001), pp. 256-272. 25. Sibley, "Why the Mona Lisa May Not be a Painting," p. 256.

26. Salmon Rushdie, Wizard of Oz (London: British Film Institute, 1992), p. 45.

27. For similar reasons I find Peter Van Inwagen's "main objection" to my theory concerning the ontological status of fictional entities- that it just "doesn't seem to be true" that speakers who utter certain sentences apparently referring to fictional characters are "engaged in any sort of pretense"to be hardly an objection at all. Van Inwagen, "Existence, Ontological Commitment, and Fictional Entities," in The Oxford Handbook of Metaphysics, ed. Michael J. Loux and Dean W. Zimmerman (Oxford University Press, 2003), p. 137.

28. Peter Kivy, “Differences,” pp. 128, 131.
29. Peter Kivy, Philosophies of Arts: An Essay in Differences (Cambridge University Press, 1997), p. 1. See also Kivy, "Differences," p. 128.

30. In Jorge Luis Borges, "Funes the Memorias," in Labyrinths: Selected Stories and Other Writings, ed. Donald A. Yates and James E. Irby; trans. James E Irby (New York: New Directions, 1964), pp. 65, 66.

31. Kivy, "Differences," p. 128.

32. Peter Kivy, "Is Music an Art?" The Journal of Philosophy 88 (1991): 544-554, see p. 553.

33. Compare my "What Is Abstract About the Art of Music?" The Journal of Aesthetics and Art Criticism 46 (1988): 351-364.

34. Kivy, "Differences," p. 131.

35. Compare my "What Is Abstract about the Art of Music?" and my "Listening with Imagination: Is Music Representational?" The Journal of Aesthetics and Art Criticism 52 (1994): 47-61.

36. See my “'It's Only a Game!': Sports as Fiction," in In Other Shoes (Oxford University Press, forthcoming).

37. This is a revised version of my 2004 Presidential Address for the American Society for Aesthetics. Special thanks to Jamie Tappenden and Jessica Wilson. 